\title{
MARITIME EDUCATION IN THE AGE OF AUTONOMY
}

\author{
ROBERT KIDD \& ELIZABETH MCCARTHY \\ SUNY Maritime College, USA
}

\begin{abstract}
Increased autonomy is inevitable aboard ships, and educators need to be preparing the mariners of the future for this eventuality. This paper will provide a brief overview of current and projected shipboard autonomy, incorporating views of unmanned vehicle researchers and licensed mariners, from 3rd mates and 3rd engineers to masters and chief engineers. From this background, projections about how the deck and engine officer roles are expected to change in the coming years will be presented. Understanding the future of these officers is critical to equipping our current students to be successful and relevant throughout the length of their careers. For example, a fully autonomous vessel, one that does not need human feedback, would be able to navigate and make decisions on its own, but may still need crew onboard to perform maintenance tasks and repairs. While a bridge crew may not be required while underway, deck officers will be needed to develop and improve the algorithms behind the autonomy. Additionally, a bridge crew would need to be available if the situation becomes too chaotic for the autonomy to navigate safely. Engine officers on the vessel will need to be able to troubleshoot and repair not only the mechanical components of the vessel but also the components that serve as the brain of the vessel. In both cases, the crew will need additional training to appropriately prepare them. This is just one potential configuration for a vessel. For other configurations, such as an unmanned vessel controlled from a shore-based control center, different skill sets will be required. However, between all of these, unifying concepts can be extracted, such as the ability to code. Identifying these now will allow maritime institutions to develop foundational courses which can be built upon as the requirements for future mariners become clear.
\end{abstract}

Keywords: future education, autonomous vessels, deck, engine, officer training.

\section{INTRODUCTION}

Change is inevitable, not always welcomed, but frequently barges through our front door. In the last 20 years, the shipping industry has seen immense change; from the introduction to ECDIS to a fully integrated bridge. These changes were mandated on the premise that safety of both our crew and our ship was priority one. One change that is roaring in is autonomous vessels. The shipping industry is usually not proactive in terms of changes. If you look just in the previous 40 years of US shipping history, changes are based on previous, sometimes disastrous, events. An example of this is the sinking of the Marine Electric in 1983 off the coast of Virginia where 3 of the 34 crew members survived. This deadly accident created the US Coast Guard rescue swimmer program in addition to requiring survival suits for winter North Atlantic voyages [1] [1]. Another example is the Exxon Valdez which in 1989 spilled 10.8 million gallons of US crude in Prince William Sound causing one of the largest and most environmentally destructive spills in US history (up until the explosion on the oil rig DeepWater Horizon in the Gulf of Mexico in 2010). The response to this was the Oil Pollution Act of 1990 which, among many co-parts, included the phasing out of single hull tank vessel [2] [2]. While the industry is no proactive, at least we can say that we take what we learn from our failures and apply it to the future of the shipping industry, hopefully making it safer for future mariners. But there is a new concept on the horizon that many mariners feel is a threat to them and the industry as a whole: the introduction of the autonomous vessel. We, as mariners, cannot wait passively to see where this new technological advance takes the industry. We must be proactive so that we can be a part of this change instead of a discarded by-product. 
As maritime educators we strive to introduce new and innovative ways to teach our future mariners. We try and stay abreast to the new technological advances that the students will be introduced to during their first few years out at sea. The introduction of autonomous and semi-autonomous vessels is daunting for mariners and educators because it means drastic change, which ultimately minimizes the requirement of crew and officers onboard the vessel while shifting what needs to be taught. In fact, this has already been happening to mariners over the last 30 years. Ships have been getting bigger and bigger, but the required crew and officer compliment has not changed. For certain types of ships, it actually takes far less manpower to successfully navigate between two points than it did in the early 1990s. The problem is this trend is accelerating and the industry is not simply discussing the minimization of crew but the complete removal of them. The problem is that if mariners do not move with this change, they will be left behind, with no say on the forward motion of the shipping industry. Before we can discuss how to deal with this change, we first need to understand what exactly this change is and how it will alter our perception of maritime education in the future.

\section{AUTONOMY BACKGROUND}

\subsection{Current autonomy}

Fully autonomous vessels do exist today, such as the ferry, the Falco. This vessel, as of January 2019, had over 400 hours of tested sea time traveling a short route near Turku, Finland. The Falco can operate with no crew onboard and is able to set a course and analyze and correct for potential hazards while under way. If there is a problem, a licensed Captain can take the controls landside and maneuver the vessel [3] [3]. So, is it a huge jump from this small ferry to a 1,400-foot container ship? It depends on which side of the argument you are on, for instance the mariners would of course say yes. Navigating a smaller vessel versus a larger vessel is fundamentally different. On the other hand, the automation engineers would argue that programming for both would be similar and that it would just be a mathematical calculation to take the size of the vessel into consideration. So, who is right? It may help to reach beyond the horizon of the shipping industry to see how automation has affected us already.

Aviation has also gone through a significant change over the last 40 years, but it is a misconception that "planes fly themselves". Planes are controlled by autopilots and automatically updated flight management systems, referred to as "Fly-by Wire systems". This automation includes setting courses, switching navigational radio frequencies, and other miscellaneous duties that previously kept pilots busy. Modern jetliners even have the capability for automatic landing, called auto-lands. Like ships, these airplanes have an autopilot, but that system is neither independent nor autonomous. It is incapable of thinking on its own. It is still told what to do by the pilot. The pilot is still the one who is instructing the autopilot on what path to take, how to descend, and so forth. These systems do roughly $95 \%$ of the work, everything except take-off and landings. While many aircrafts can auto-land, less than $1 \%$ of all landings are performed this way and all take-offs are performed manually. Despite the increased automation, pilots are still in charge of the planes [4] [4].

Although aviation statistics have gotten increasingly better over the years, there are still accidents. Most of the time, it comes down to human error because although the systems are controlling the plane, it is following the instructions from the pilot. It is ultimately the pilot who is interpreting the alarms, making a decision based on the readings of the computer-based system on board, and dictating a plan of action [5] [5]. This is very similar 
to the shipping industry. The computer systems onboard will alert us to potential hazards, but it is ultimately up to the officers on how to proceed based on the data given by the computers. Commands are then given to computerized systems which execute the officers' plan. Is this not what ultimately makes the difference? How people use the technology they are given. Why hasn't the aviation industry become fully automated yet and why is it not as big of a discussion as it is on the shipping side? There may be a very simple answer to this question: fear and payload. How comfortable is the general public getting into a commercial plane that has no pilot? Likely, they would not, but companies are testing the waters, such as Uber Air. What about cargo planes? The public may feel comfortable with unmanned planes in the skies, but the owners of the goods in transit may not, though again companies are testing this, such as Amazon's delivery drones. This demonstrates the point. It's not a fear of the technology that is slowing implementation, but a fear of losing the payload.

One major argument against autonomy is that pilots are better than computers at quickly analyzing data and reacting to strange situations. A perfect example is when Captain Sullenberger landed in the Hudson River in January of 2009 without a single casualty. Could a computer have done that, could a computer technician have programmed that plane to simulate birds flying into the engine and created a successful outcome? We will never know the answer to that, but it is one of the reasons pilots are still in control of their planes.

This argument persists on the shipping side with the belief that it is impossible to compute our way out of every dilemma or complication. It is the reason why the concept of fully autonomous vessels is more far reaching then the concept of semi-autonomous vessels, at least in the near future. This is similar to how the aviation industry is driven. Pilots will remain on board for arrivals and departures and as "back-up" to the computer systems on board. This premise is similar to the officer compliment on a semi-autonomous vessel.

\subsection{Long-term future autonomy}

To discuss how autonomy could potentially affect future mariners, additional background on some of the potential implementations of autonomy must be discussed. Tugboat operations are a perfect place to explain some of the terminology the automation industry uses and the different skills required. The autonomy can loosely be clustered into four levels: full autonomy, supervised autonomy, semi-autonomy, and no autonomy. A fully autonomous vessel is capable of observing the world around it, deciding what it should do, planning out a way to achieve that goal, and executing it, all without human intervention. An example would be a fully autonomous tug that identifies an incoming vessel needs assistance, plans a path that takes the tug and the vessel to the appropriate dock, and then maneuvers along that path. If a human takes part in this, for example, a docking pilot on the vessel's bridge tells the autonomous tug what they want the tug to do but doesn't tell the tug how to do it, this would be supervised autonomy. Usually a vessel with full autonomy or supervised autonomy would have an unmanned bridge but they may not necessarily be completely unmanned. The shipping industry generally refers to both full and supervised autonomy as full autonomy.

One of the major difficulties with an autonomous tug is line handling. While certain tug companies have begun to explore avenues to automate this process, being unable to do this without humans would not prevent a tug from being autonomous. The tug could have humans onboard that would be able to manage the lines. Alternatively, that tug may require humans to operate and manage the engine room. Just because the tug is not directly controlled by a human does not mean humans cannot work on it.

Semi-autonomous vessels cover anything between the cases listed above and the modern vessel. This is a huge category, obviously, and it will certainly look different in different 
environments. For the tugboat, one of the major challenges is the operating environment. Tugs operate in heavily congested waters where both professional and amateur mariners are active along with pleasure craft and possible debris. Identifying all of these obstacles and determining the appropriate path is an extremely difficult problem for the autonomy. However, navigating the desired path is relatively straightforward. Vessel dynamics have been heavily studied for centuries and the autonomy would likely be extremely familiar with the response of the vessel itself due to the large volume of data it would be able to collect.

This is a prime candidate for autonomy to collaborate with deck officers. The autonomy can present the deck officer with a detailed view of what it sees in the environment (i.e. vessels, pleasure craft, debris, etc.), along with the velocity and probable trajectory of all items it has identified (similar to a hurricane tracking path), and what it believes is the best path through the environment. The deck officer would then have the opportunity to correct the autonomy, pointing out obstacles the sensors missed or misidentified, or assumptions that the autonomy made that are not valid. The officer could tell the autonomy to recompute a new path according to this information or could direct the autonomy to change its course directly by shifting the path in one direction or another to give a particular object a larger berth, for example.

Once the officer has approved the path, the vessel can begin to navigate it. Both the autonomy and the officer will be looking for new hazards or changes in the behavior of any of the objects that can currently be seen. Sometimes, the officer will have a "gut feeling" that something is going to happen and can work with the autonomy to plan ahead in case something happened. Other times, the autonomy alert the officer that an object has change behavior before the officer notices it because the autonomy can look in all directions simultaneously and be able to detect smaller changes due to its sensor sensitivity.

For the autonomy community, this is a good option. It marries the best attributes of both humans and machines, provides an additional layer of safety where the human and the machine are checking each other for errors, and puts a human in the loop to make final decisions that could endanger lives and cargo. This minimizes the potential for accidents while also providing someone who is ultimately responsible for the safety of the ship, the crew, and the cargo.

Again, it should be emphasized that this is one option for one application of autonomy. This also does not even consider how this would be implemented in practice. In an emergency, designing an interface that allows a human to make override commands if necessary is a major conversation. An even more controversial question is whether the deck officer working with the vessel would need to be on the bridge or whether modern simulators can sufficiently replicate the on-board environment.

For the vessel operating near-shore, it is entirely possible to be run unmanned, but it is unlikely to be fully autonomous. The complexity of the near-shore environment means the chances are too high that complex situations will arise that the autonomy is insufficiently prepared for. The aforementioned Falco is an easy example. The vessel's route is short and the vessel is relatively small, but it is still closely monitored. The system could theoretically be run unmanned as long as virtual or physical support can reach the vessel reliably. If something were to go wrong, support crews would need to reach the vessel quickly from shore. Of course, "quickly" is an important term in this case. This type of vessel carries very precious cargo, people. If an emergency should arise and the passengers needed to abandon ship, would it be safer and more efficient to have trained personnel onboard or depend on support services to travel to the vessel from a shore-based facility.

The circumstances that make the unmanned near-shore vessel a possibility also make it unlikely to be the template for how autonomy could be implemented everywhere. With so 
many different types of vessels, realistically, only certain types can be fully autonomous. As an industry we seem to agree on one thing: semi-autonomous vessels are the first hurdle. Increase the size of the vessel and place a couple hundred million US dollars' worth of cargo on her and many fewer people are willing to run the risk of it running fully autonomously. The obstacle is not the ability for the programmers to come up with AI systems that safely navigate this vessel across the Pacific Ocean, but the inherent fear that, although a small, there is a chance for something to go wrong. If there are no humans on board the potential is huge for loss of cargo and vessel, going into the hundreds of millions in losses.

Because of this, the most likely scenario for cargo vessels in the near future is therefore a semi-autonomous vessel with a small license crew on board to ensure that nothing does go wrong until the reliability and safety of these systems can be determined. This is not to say that full autonomous cargo vessels will never come to fruition. But arguably semi-autonomous are more realistic for the near future and therefore, as educators, we need to help prepare the mariners of the future for these vessels.

\subsection{Near-future projections for the shipping industry}

As previously discussed, the path for unmanned ships has already begun, with the introduction of the Falco and the Yara Birkeland. Both vessels are described as fully autonomous but will be manned outright until all the bugs of the AI systems have been fully worked out. The Yara Birkeland will be a cargo vessel mainly carrying fertilizer and is expected to be "fully self-guided" by 2022. The vessel will carry cargo from Yara's Porsgrunn production plant to Brevik and Larvik in Norway. Like the Falco ferry, the run is short and can easily be monitored from shore. The Falco used Rolls-Royce intelligence technologies to successfully transport 80 people from Parainen to Nauvo Finland in 2018. The ferry was also able to auto-dock without human intervention. The collaboration between Finferries and Rolls Royce is called the SVAN project (Safer Vessel with Autonomous Navigation) [6] [6]. So, what will be rolling out of the shipyards in the near future? China and Japan have both jumped on the bandwagon with remote controlled vessels expected by 2025 with more and more discussion opening every day about the future of fully autonomous shipping [7] [7]. Although most discussion for these automated vessels are small scale, we have learned over the years in the shipping industry, we like to see just how big we can go. Recently the US Navy has requested $\$ 628$ million for research for the development of Unmanned Vehicles, Large Unmanned Surface Vehicles, Medium Unmanned Surface Vehicles and Extra Large Unmanned Undersea Vehicles [8] [8]. The world is turning to automation quickly with the conception that, although it may take years to become fully automated, it will be a reality within our lifetime and within our students' careers. Realistically ocean-going vessels on long routes are not in the near future, neither are large scale passenger vessels. However, as maritime educators, we need to stay abreast to the ever-changing scale of the shipping industry.

\section{EDUCATION}

The different levels of autonomy that could be implemented in different vessels require different skill sets for those who will be operating them. While eventual specialized training is essential, the educational community simply cannot address all of them while providing sufficient depth in any of them. Therefore, the traditional primary target for the maritime education will be considered in detail: the ocean-going cargo vessel. Additionally, because they are seen as the cutting-edge in terms of shipboard autonomy, the implications for near shore vessel will also be addressed. 


\subsection{Engine officers}

The engine officer of the future will likely need to specialize into either an optimization and programming role or a maintenance and repair role. Under normal operating conditions, the engine room of these vessels would not require an engine officer present. However, two major factors make it highly probable that these individuals will always be required to be on-board: the operating conditions will not always be normal, and maintenance will be required to keep operating conditions normal for as long as possible.

The maintenance tasks would likely not require a high-level degree, but this will not be the case for abnormal operating conditions. One of the few guarantees in life is that things will break, and they will do so at the least opportune time. As such, someone with detailed knowledge of the engine room must be available to make repairs the automation simply cannot do. While it is possible that instructions on how to make these repairs could be sent from shore, there would be no way to do so if communications were damaged as well.

A possible avenue would be for the vessel to have enough redundancy to allow the vessel to continue operations despite needing repairs. This is an interesting option but would not lead to full unmanned operations. The penalties of the additional redundancy in terms of cost and cubage would be huge. Plus, the vessel would need to be repaired in port since it lacks crew quarters. Because no crew would be onboard during transit, no maintenance tasks would be performed while underway, leading to an increased number of repairs, an increased severity of damage, and increased down time in ports. This does not consider issues such as communication failures or breakdowns that occur during hazardous environments. As such, these issues will likely combine to mean ocean-going vessels will likely require a crew at all times. On the other hand, near-shore vessels could follow this route depending on their uses.

Training these officers will follow a similar track to current engine officers. They will need a detailed knowledge of how the system operates. However, they may not need as much information on the theory behind it, as this information can be provided from shore. The crew would need detailed information on the theory behind the communications systems, as they would not be able to obtain additional information on it during a repair. The reduced theoretical training would allow time for the additional training required for these systems. Additional topics such as cybersecurity would be beneficial as well.

To facilitate this educational change, adjustments would need to be made in the coursework required. At SUNY Maritime College, as at other institutions, the students are already at or approaching the credit limits. This means that the Engineering department will need to adjust current offerings to address these new needs while still satisfying the current requirements for licensure. For example, all license engineering students are required to take a 2-credit programming class and three 3-credit electrical engineering courses: introductory circuits, electric machines (e.g. motors, generators, and power distribution), and advanced circuits. The introductory circuits class is critical to any engineering major, but the other two could be heavily modified. Focusing one on the operations and control of motors and generators will give the students the advanced knowledge they need to repair and interface with modern control systems. Focusing the other on the transmission of information and power will enable the students to understand the fundamentals of the advanced communication equipment involved and the increasingly electricized vessel. Students interested in an electrician or electro-technical roll would need to pursue additional training or enroll in the Electrical Engineering degree. These students would gain training in control system theory, advanced programming, machine learning, and communication theory.

These changes would prepare the average engineer to pursue what interests them while giving some flexibility for future requirements. It should be noted that the above changes 
would not be enough, but they are a start which is net-neutral on credits. Some advanced programming coursework and possibly some machine learning would be recommended for all engineers and some additional work focusing on understanding instrumentation and measurement would be greatly beneficial as the future mariners will likely continue to deal with increased automation in the engine room. However, the 5-10 credits needed to teach these courses would require space to be made in the curriculum.

The optimization and repair role will likely be focused on ensuring the ships in the fleet operate as efficiently as possible while minimizing downtime. These engineers will be heavily involved in analyzing and interpreting large data sets, predicting potential failures, integrating new hardware/software, and evaluating the performance of the autonomy. These individuals will need to have an intimate knowledge of shipboard systems to be able to understand the effects of their changes and the potential causes of failures. They will also likely need to be fluent in the engine room terminology and equipment to be able to communicate with the maintenance and repair engine officers on-site to explain repairs and to collaboratively determine the best solution to a problem. However, these officers will also need to be able to perform many high-level computer science tasks like data analysis, programming, and complex optimization. Much of this can currently be seen in the research put forward on the concept of the "digital twin", a virtual copy of a system that utilizes data from the physical system for analysis and prediction.

As such, these engineers will likely be required to take courses on advanced programming, machine learning, "big data", optimal problem solving, and advanced controls. Comparing this to this to the offerings directed toward licensed mariners, nothing currently approaches this program. This is essentially a computer science or computer engineering degree with a license component and would represent an enormous shift in the industry. Fortunately, it is not expected to happen suddenly. What will likely happen initially, is the industry will have an increased demand for licensed engineers who have some of these skills. The training institutions will need to adapt to the demand by offering more courses and eventually more majors based on this information. The infrastructure required for these changes would likely involve additional staff in the electrical department and, possibly, the addition of true computer scientists to the faculty. This would be especially true for shore-side support roles.

\subsection{Deck officers}

Redundancy is an apparent theme in the shipping industry. As automated as the bridge equipment has gotten over the last 20 years an officer remains a core element of the bridge. On modern vessels we have a secondary ECDIS to our primary ECDIS or paper charts as backup. Additionally, we require deck equipment to have back up reserve power. We strive to always be ahead of the worst-case scenario. With the introduction of AI systems, how can the safe navigation of a ship be guaranteed? The simple answer is that it cannot, so the deck officer remains a component of the integrated bridge for the near future. As systems evolve and trust in the AI system increases, the need for the currently trained deck officer onboard will phase out. This is a common practice in this industry. We have phased in regulations over the years; phasing out single hull tankers, phasing in air emission regulations, and phasing in bridge equipment upgrades (ex. Upgrading from grease pencil to ARPA systems on our radar), to name a few. A simple problem to autonomy is that we cannot snap our fingers and make all vessels sailing on the oceans autonomous overnight. This creates a cross over time where ships are navigated by people and computers.

Open ocean navigation is entirely different that coastal navigation, thus the reason we test deck officers differently for these two areas. The deck officer, initially, aboard a 
semi-autonomous ocean vessel would be the back-up for emergency situations, for example hurricanes or other emergencies at sea. Deck officers aboard semi-autonomous coastal vessels would be more hands on, actively checking the equipment and serving as the pilot and look out for the vessel, checking the decisions of the AI system and acting accordingly. Both these positions would continue to demand that the officer have shipboard experience, navigation and safety instruction, and computer skill set. The deck officer's academics would remain, for the most part, unchanged in terms of navigation and safety training.

Although the AI systems would control the ship the deck officer would still be the "back-up" and trained accordingly to take over the control of the ship if necessary. This means the deck officer must be able to interpret and analyze the data sent to the AI and must understand why the AI made a given decision. They must have training on safe navigation of the ship and the core principles the AI system is using. Supplemental classes for programming would have to be included in the deck curriculum as the ship becomes more and more automated. The hierarchy of the vessel would not change immediately; there must be a person responsible for the vessel, the cargo and the crew. The Captain of the vessel remains as the head of the ship, currently this cannot be replaced by a person on land because of the delay in command and the need for onboard leadership. But as the industry relies more and more on AI systems and continuous connectivity becomes more reliable, the Captain will be moved landside as the OIC (Officer in Charge). The concept of third mate, second mate and chief mate would initially remain the same but as the AI system becomes more and more operational and the trust grows with the system, the deck officer will be molded into something this industry has colloquially dubbed a "deckineer" or hybrid officer.

\subsection{Hybrid officers}

The hybrid officer would need to be skilled in topics that are traditionally housed in both the engineering department and the deck department. The question for educators becomes how do we train these officers going forward? It is very difficult to answer this question simply because we do not know for certain what the future holds for our industry or how long it will take for that future to come into realization. But we can predetermine the training needed for an average officer on board based on what we know is required today.

These new positions will be multi-functional and trained accordingly. We envision the future officer to be educated in core elements of engineering, thus graduating with a Bachelor of Science or Bachelor of Engineering, but trained in the deck systems of a ship. Classes such as; Terrestrial Navigation, Electronic Navigation (including the use of ECDIS, Electronic Display and Information System), Radar, Bridge Resource Management and Ship Handling, Rules of the Road, GMDSS (Global Maritime Distress and Safety System), and Ship Stability. These classes would have been adapted and may not be simply one lecture or lab class. Today the current curriculum for a deck/engine officer demands approximately 32-36 additional credits added to their core curriculum. Adding more classes for cybersecurity, engineering systems and programming would place too much of a heavy course-load for these students therefore combining required classes and diminishing archaic requirements could potentially open space for additional deckineer case work.

\subsection{Company training}

The industry today is highly variable in terms of size, vessel type, and cargo carried. This creates complications for the education of future mariners working with semi-autonomous and, one day, fully autonomous vessels. There will be gaps in the future of maritime 
education because we cannot fully train every student for the AI systems coming online within the industry. Automation is happening quickly and receiving maritime education is a 4 -year process. In the early 2000s when grease pencil radars were being replaced with ARPA units, the students graduating were required to have additional training for ARPA after graduation, the upgrade happened quickly, and the maritime schools played catch up to the industry. We fear this will be the same problem with the AI systems. The solution will have to be additional training by the companies for their specific AI systems and ship types. Communication between what is needed and required by the industry is essential if the mariners of tomorrow are to be prepared and appropriately trained.

Most maritime institutions do not have the background experience to simply pivot what is taught to these needs. Industry will need to communicate their desires to the institutions early so that the workforce they need can be trained and ready. For example, none of the maritime academies in the United States offers a Computer Science or Computer Engineering degree. Adding the faculty to support this change will likely require significant capital investment and time. Most of these new faculty members would come from outside the maritime industry, and so would need to learn about it before they can begin tying their expertise into the mariner's education. Estimates are that because some of these changes are so different from what is currently offered, it could take up to 10 years from when the need is first noticed, to when the first cohort graduates. The sooner industry can communicate what skills will be needed, the sooner these mariners can be trained.

\section{CONCLUSION}

In the shipping industry we have always strived to perform safely. The last thing we want to see on CNN is a picture of a ship spewing oil into the ocean or on fire with heavy black smoke billowing up into an already clogged atmosphere. Unfortunately, we have seen these images many times and these accidents usually arise from human error. The industry wants to fix this, but we must be careful and do this correctly. If it is done too fast and an accident occurs with a large loss of life or cargo it could set the industries timeline for autonomy way behind. The response to recent crashes involving Uber and Tesla autonomous cars have demonstrated this. When the technology is pushed forward too fast for the wrong reasons, incidents occur, and the entire industry gets held back. The industry has always believed in the "back-up" system, it is the primary reason for teaching deck cadets celestial navigation today. Lifeboatman certification is still required on every vessel even though abandoning ship is a last resort. Even with the introduction of ECDIS on our vessels a secondary system is still required, be it another ECDIS on a different power system or the old paper chart method. We seem to believe that it is needed and even with the introduction of AI systems aboard our vessels we will need a mandated back-up system too. The concept of autonomy is fantastic but not as easily attainable in the near future as many think. A simple timeline of evolution must be created and discussed by all parties involved: mariners, automation experts, legal experts, and educators. This timeline will take into consideration the advances in technology and the change in the training of the modern mariner. As mariners we need to be part of this change, we have successfully navigated these waters before; from the introduction of automated systems to something as monumental at the time, allowing women to work on ships. We can help create a safer shipping industry for today and for tomorrow. As educators, we need to be a part of this change to ensure are graduates are equipped to evolve with the industry. 


\section{REFERENCES}

[1] Zilnicki, C., Multimedia Release: The Shipwreck that Changed the Coast Guard Forever; United States Coast Guard, US Department of Homeland Security, 2019. https://content.govdelivery.com/accounts/USDHSCG/bulletins/22ecflc. Accessed on: 17 Jun. 2019.

[2] Exxon Valdez Oil Spill, Editors of Encyclopaedia Britannica, Encyclopaedia Britannica, 2019. www.britannica.com/event/Exxon-Valdez-oil-spill. Accessed on: 17 Jun. 2019.

[3] Morris, D.Z., World's First Autonomous Ship to Launch in 2018; Fortune, 2017. http://fortune.com/2017/07/22/first-autonomous-ship-yara-birkeland/. Accessed on: 17 Jun. 2019.

[4] Smith, P., We Are Told that Planes Basically Fly Themselves. How True is This?; Ask the Pilot, 2013. www.askthepilot.com/questionanswers/automation-myths/. Accessed on: 17 Jun. 2019.

[5] Webster, A., Automation, Risk, and Airplanes Without Pilots; International Risk Management Institute Inc., 2013. Www.irmi.com/articles/expert-commentary/ automation-risk-and-airplanes-without-pilots. Accessed on: 17 Jun. 2019.

[6] Gibson, R., Rolls-Royce and Finferries Demo World's First Fully Autonomous Ferry; Cruise \& Ferry, 2018. www.cruiseandferry.net/articles/rolls-royce-and-finferriesdemo-worlds-first-fully-autonomous-ferry. Accessed on: 17 Jun. 2019.

[7] Autonomous Shipping Makes Waves, Hellenic Shipping News, 2019. www.hellenicshippingnews.com/autonomous-shipping-makes-waves/. Accessed on: 17 Jun. 2019.

[8] O'Rourke, R., Navy Large Unmanned Surface and Undersea Vehicles: Background and Issues for Congress, Congressional Research Service: Washington, DC, 2019. 